\title{
PRESSÃO DE LÁBIOS E DE LÍNGUA EM CRIANÇAS RESPIRADORAS ORAIS E RESPIRADORAS NASAIS: CARACTERIZAÇÃO E COMPARAÇÃO
}

\section{Maria Fernanda Bagarollo, Aniely de C. Pereira*}

\section{Resumo}

O padrão típico da respiração é realizado de forma nasal. Porém, quando esse padrão é impedido de ser realizado, a partir de fatores como obstrução nasal, a respiração é realizada de forma altera pela cavidade oral, na qual o indivíduo realizará uma respiração mista. Esse novo padrão respiratório irá causar diversas consequências, entre elas a diminuição de pressão de lábios e de língua. O estudo então investigou essa pressão de lábios e de língua em 30 crianças respiradoras nasais e 30 crianças respiradoras orais, na faixa etária de três a 12 anos. Divididas em Grupo Controle (GC), não apresentam diagnóstico de respiradoras orais e Grupo Estudo (GE), porém diagnosticadas como respiradoras orais. A partir do estudo foi possível concluir uma diminuição na pressão de lábios e língua nas crianças respiradoras orais.

\section{Palavras-chave:}

Respiração Oral, Crianças, Força de lábios e língua.

\section{Introdução}

A respiração, quando alterada, é realizada de forma oral, na qual o indivíduo substitui o padrão nasal por uma respiração, predominantemente, oral. Essa alteração pode ser causada por fatores diversos, entre eles o mais comum é a obstrução nasal ${ }^{1}$. A literatura afirma que uma das consequências da respiração oral é uma diminuição da pressão da língua e dos lábios, a partir de estudos realizados com o lowa Oral Performance Instrument (IOPI) equipamento que mede a pressão da língua, mas ainda existem poucos estudos sobre tais consequências ${ }^{2}$. O objetivo do estudo foi caracterizar a pressão dos lábios e da língua nos grupos de crianças respiradoras orais e respiradoras nasais, comparar a pressão dos lábios das crianças do grupo estudo (respiradoras orais) com as crianças do grupo controle (respiradoras nasais) e comparar a pressão da língua das crianças do grupo estudo com o grupo controle.

\section{Resultados e Discussão}

O estudo foi realizado com 60 crianças na faixa etária de 3 a 12 anos. As quais foram divididas em Grupo Controle (GC), composto por 30 crianças que não apresentam diagnóstico de respiradoras orais e Grupo Estudo (GE), também composto por 30 crianças, porém diagnosticadas como respiradoras orais. O equipamento nacional para medir a pressão de lábio e língua é o de Pressão de Lábios e de Língua - PLL (Biofeedback Pró-Fono: Pressão de Lábios e de Língua -PLL Pró-Fonoß), o qual tem como função quantificar a pressão dos lábios e de língua. Essa medição é realizada através de um transdutor inserido entre os lábios na posição horizontal quantificando a pressão do músculo orbicular de boca, e quando esse transdutor é inserido dentro da cavidade oral e pressionado contra o palato duro apenas com a ponta da língua ou com o dorso da língua, é possível a quantificação da pressão de ponta e/ou dorso da língua ${ }^{3}$. A partir dos dados coletados, os resultados obtidos foi uma pressão dos lábios e da língua nas crianças respiradoras orais inferior as respiradoras nasais. Porém, o equipamento apresenta um bulbo de ar muito grande, o que gerou um número significativo de crianças que não conseguiram pressionar o bulbo.

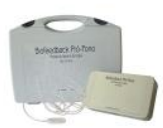

Figura 1. Biofeedback Pró-Fono: Pressão de Lábios e de Língua (PLL Pró-Fono) e o dispositivo bulbo de ar

\section{Conclusões}

Há uma diminuição da pressão de lábios e de língua das crianças do grupo controle, se comparadas com o grupo estudo.

\section{Agradecimentos}

AME/Santa Bárbara d' Oeste e PIBIC/Unicamp e CNPq

\footnotetext{
${ }^{1}$ NISHIMURA, C. M.; GIMENEZ, S. R. M. L. Perfil da fala do respirador oral Rev CEFAC, v. 12, n. 3, p. 505-8, 2010.

${ }^{2}$ MOURA, K. I. S.; CUNHA. D. A. Avaliação quantitativa da pressão de língua em crianças com respiração oral. In: CONGRESSO DE INICIAÇÃO CIENTÍFICA DA UFPE, 2014. Recife.

${ }^{3}$ Biofeedback Pró-Fono. Pressão de Lábios e de Língua -PLL Pró-Fono. 20016 Disponível em:

<http://www.profono.com.br/produtos_descricao.asp?lang=pt_br\&codigo_categ oria $=1 \&$ codigo_produto=229> Acesso em: 8 de Jun. 2018
} 